
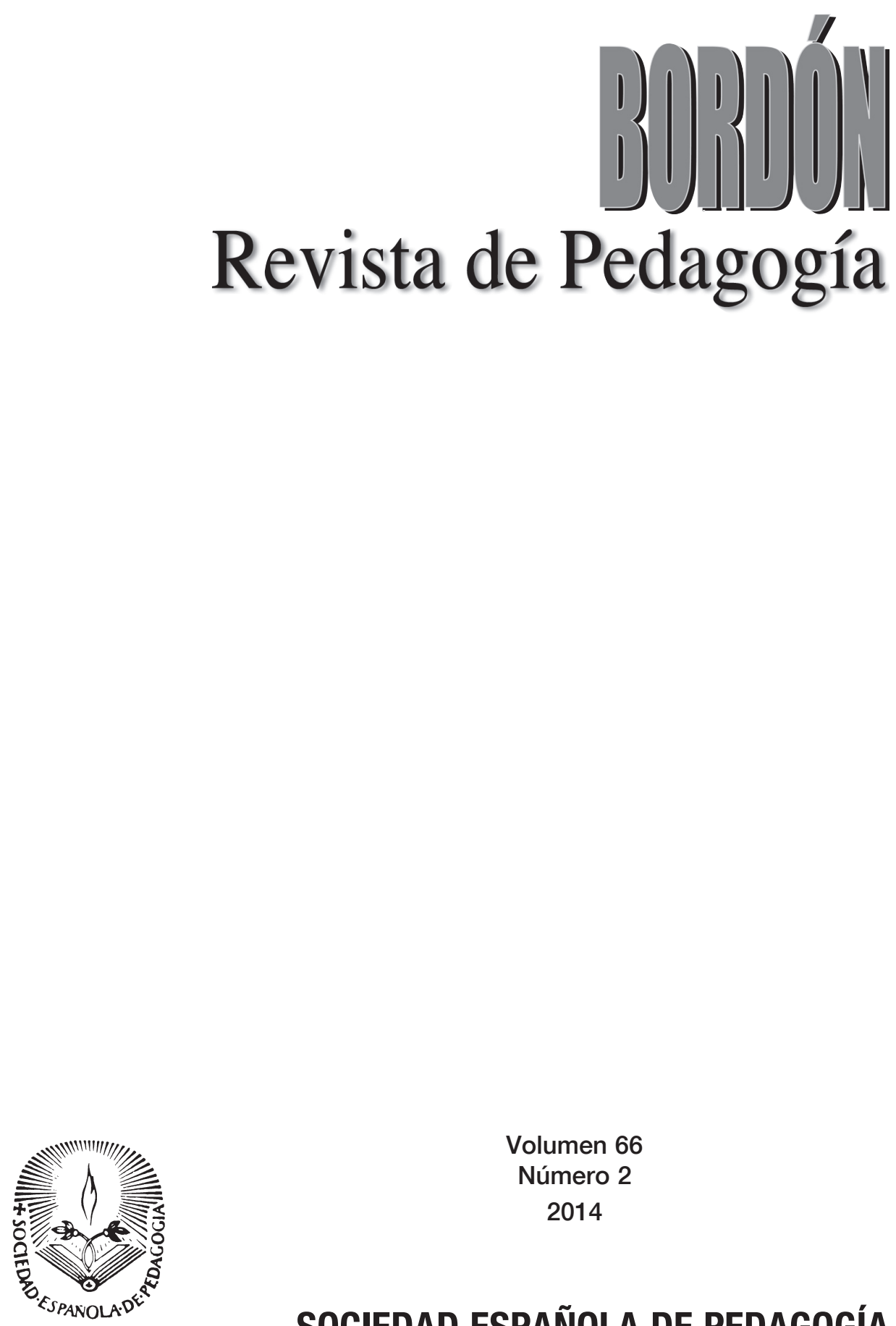

Volumen 66

Número 2

2014

SOCIEDAD ESPAÑOLA DE PEDAGOGÍA 


\section{EDITORIAL / LETTER FROM THE EDITOR}

\section{Eualuación de la producción científica en educación. ¿Una nueva crisis? \\ Educational research evaluation. A new crisis?}

ARTURO GALÁN

Director/Editor-in-chief de Bordón. Revista de Pedagogía

DOI: $10.13042 /$ Bordon.2014.66200

Nos encontramos en un momento delicado de la universidad española. La crisis económica ha generado un aumento de la presión sobre el profesorado universitario como consecuencia de la paralización de la convocatoria de nuevas plazas y los drásticos recortes en I+D. La plantilla de profesores se ve obligada a asumir la carga docente de los colegas jubilados mientras se reducen los sueldos y se rebajan los fondos para financiar proyectos de investigación. A ello se suma un sustancial incremento del tiempo requerido para el uso de plataformas digitales (Tirado y Aguaded, 2012) y para la realización de tareas burocráticas. Sin embargo, las evaluaciones de la productividad y de la calidad a las que se somete a un profesorado sobrecargado y a una universidad con los recursos mermados no han disminuido ni en número ni en nivel de exigencia.

La evaluación de la producción científica española en el campo de la educación ha sido muy controvertida desde sus orígenes, sobre todo desde que diera lugar a incentivos económicos mediante los conocidos tramos o sexenios de investigación (RD 1086, 1989). La Sociedad Española de Pedagogía, editora de Bordón, ha jugado un papel importante en los últimos años como correa de transmisión del malestar existente entre la comunidad científica educativa por la forma de llevar a cabo esta evaluación por parte de la Comisión Nacional de Evaluación de la Actividad Investigadora (CNEAI). Prueba de ello fueron los dos documentos firmados por nueve sociedades científicas en 2009 y $2013^{1}$.

Entre las propuestas que se hacían en el último documento podemos destacar aspectos que pueden parecer obviedades como la necesidad de que se realice una evaluación con garantías de objetividad, transparencia y publicidad, junto con una necesaria motivación de las evaluaciones negativas. Ciertamente son aspectos básicos que deberían estar presentes en cualquier programa de evaluación de personas (más aún si tiene implicaciones para la promoción, retribución, etc., es decir, afecta a la limitación de derechos), pero que ha sido necesario recordar a los responsables de la CNEAI por la reiterada falta de claridad y precisión de las convocatorias.

Además de esas propuestas básicas, se hacían otras de mayor calado que posibilitan, a partir de un baremo bien definido, objetivar las evaluaciones 
a partir de la clasificación de las revistas según índices internacionales como el JCR de la Web of Science, el SJR de Scimago o el ERIH de la European Science Fundation (que acaba de ser transferido para su mantenimiento a la Norwegian Social Science Data Services), así como otros índices nacionales reconocidos y sostenidos con fondos públicos como DICE-ANECA, INRECS, RESH, DIALNET-CIRC, MIAR y sello de calidad FECYT. La filosofía de la propuesta es que, existiendo bases de datos reconocidas que establecen evaluaciones y rankings de revistas utilizadas en diferentes procesos de evaluación del profesorado universitario, no tiene sentido que la convocatoria de tramos de investigación sea tan ambigua que los solicitantes no puedan prever con un alto grado de seguridad cuál va a ser la puntuación asignada a sus contribuciones.

Es justo reconocer que hay voces contrarias a objetivar de este modo las evaluaciones porque podrían cometerse errores y dejarían sin función a los evaluadores de los comités de la CNEAI. También se argumenta que, evaluando así, no se juzga verdaderamente la calidad de los artículos presentados. Pues bien, ya hay experiencias institucionales que han probado la satisfacción de los profesores universitarios cuando se objetivan las evaluaciones (Galán y Muñoz, 2006). También se ha defendido que, cuando se parte de un baremo objetivo, las comprobaciones iniciales podrían realizarlas un grupo de administrativos cualificados, dejando a las comisiones de catedráticos no sin funciones, sino con otras nuevas y probablemente más adecuadas a su posición y saber: la supervisión del proceso, la consultoría en los casos que fueran dudosos y la motivación razonada de las evaluaciones negativas (Galán y Zych, 2011), consiguiendo así una mayor eficiencia de tiempo y de recursos humanos. Por otra parte, si nos fiamos de las bases de datos que evalúan revistas y del sistema de revisión por pares de las revistas científicas, no parece necesario revisar de nuevo los trabajos de los profesores solicitantes de los sexenios, pues estos trabajos ya han pasado el filtro de los editores y de los revisores especialistas. Pedir a los miembros de los comités de evaluación que se lean y valoren todos los trabajos sería algo inviable, ineficiente y susceptible de un mayor grado de subjetividad, además de no contar con la necesaria especialización.

Con el sistema indicado en el documento-propuesta de las sociedades científicas también podría haber fallos, pero seguramente menos, más fácilmente revisables y no sistemáticamente en contra de los solicitantes. Los responsables administrativos y los evaluadores de la CNEAI deben pensar que dicho documento está firmado por las nueve sociedades científicas más importantes de educación y que, si hay un acuerdo tan unánime para hacer esa petición, es porque es necesario un cambio de procedimiento. En un mundo ideal, en otra cultura de evaluación o, incluso, en el ámbito de las ciencias exactas que comparten otra tradición, posiblemente este grado de concreción para objetivar no sería tan necesario.

Si lo que se pretende con el otorgamiento de sexenios es otra cosa distinta que la que se ideó en 1989, y premiar solo una especie de superexcelencia investigadora, entonces habría que diseñar un nuevo complemento específico diferente y mucho más atractivo económicamente, hasta el punto de que fuera capaz de atraer talentos internacionales (Galán, 2013). Pero la realidad es que ni fue esa la intención cuando se decidió en el año 1989 premiar la producción investigadora mediante los sexenios, ni tal hipótesis se deriva de los textos actuales de la convocatoria, que más bien manifiestan la producción tipo que sería exigible a un profesor normal en cada campo de conocimiento. Esa premisa explica los altos porcentajes de evaluaciones positivas entre los profesores que voluntariamente se someten a evaluación. Sin embargo, no ha sido esta la tónica en el campo de la educación, donde distintos factores como la imprecisión de los criterios de evaluación y su aplicación, la mezcolanza de los miembros del comité de evaluación (con escasa presencia de especialistas en educación) y, quizá, una imaginada y cambiante concepción de la 
excelencia investigadora, han provocado un índice de fracaso inaceptablemente mayor a la gran mayoría de las áreas científicas evaluadas.

No obstante, aunque la CNEAI no ha publicado datos sobre los resultados de las evaluaciones después de 2009, parece que la buena reputación de los índices de impacto nacionales referidos anteriormente y su uso en las evaluaciones del profesorado de la ANECA, junto con el acuerdo de las sociedades científicas sobre cómo evaluar la producción científica en España y la presencia de dos miembros de educación en el Comité de 2013, ha producido una mayor claridad en los criterios de evaluación y su aplicación y, consecuentemente, una mayor y más racional tasa de evaluaciones positivas en el último año, aunque habrá que esperar a contar con datos reales.

La segunda gran preocupación que se plantea es que, con la crisis económica, los responsables políticos han decidido cortar la financiación a los grupos que crearon y mantenían los estudios de impacto de las revistas científicas de producción en castellano. Así, tres de las referencias más importantes (DICE, INRECS y RESH) han anunciado su parada por falta de recursos económicos. Lamentablemente, si no vuelve la pequeña financiación que requieren estos grupos especialistas en bibliometría para mantener dichos índices de impacto, España perdería su posición de referencia en Latinoamérica en este tipo de instrumentos y se contribuiría a rebajar de nuevo la visibilidad de nuestras buenas revistas científicas, reduciendo la producción investigadora en español evaluable —a efectos de selección, promoción o complementos retributivos-a las pocas revistas indexadas por una o dos empresas privadas extranjeras como Thomson Reuters y Elsevier, cada una con su particular estrategia en la selección e indexación de revistas en lengua no inglesa. De otra forma, se contribuiría al declive de buena parte de las revistas científicas educativas españolas de contrastada reputación y a limitar considerablemente la producción científica de calidad en castellano.
Sin duda, los investigadores españoles deben publicar en las revistas de mayor impacto y en inglés para mejorar los índices de producción científica de nuestras universidades, pero ello no debe significar que esta sea la única producción que deba ser considera a efectos de evaluación ni que las revistas españolas o latinoamericanas no publiquen también artículos de calidad similar. Por ello, pensamos que la evaluación de la producción científica debe combinar ambas vías y ser, a la vez, sensible a las peculiaridades de ciertas áreas donde el interés potencial de sus temas de investigación es mucho más limitado para tener cabida en revistas internacionales (Aliaga y Correa, 2011).

Finalmente, y en relación con lo anterior, no es pertinente despreciar la publicación de las investigaciones educativas en formato libro. El libro sigue siendo un elemento fundamental de difusión científica. Para conseguir una valoración más objetiva de dicha producción, habrá que avanzar en acuerdos bien fundamentados en los distintos campos de conocimiento y en proyectos en la línea de clasificaciones como la del $\mathrm{SPI}^{2}$ (Scholary Publishers Indicators in Humanities and Social Sciences).

Otro de los efectos de la crisis se ha hecho notar en la financiación de los proyectos de investigación, donde la educación no es precisamente un área prioritaria en la política científica internacional. Por una parte, a falta de fondos, aumenta la competitividad entre proyectos y disminuye el dinero disponible a asignar a cada proyecto. Por otra parte, se plantea de nuevo el problema de la objetividad y la coherencia de las evaluaciones de la Agencia Nacional de Evaluación y Prospectiva (ANEP) en un escenario mucho más complicado que en el caso de los tramos de investigación.

Todo lo dicho no puede ni debe desligarse de la importancia que tiene la función docente del profesorado universitario, que queda deslucida ante el fuerte énfasis puesto en la investigación, pese a los nuevos enfoques y al incremento también de la presión evaluativa en este ámbito 
(De Juanas y Beltrán, 2014). Por ello, los esfuerzos de las sociedades científicas del ámbito de la educación por clarificar los problemas existentes y hacerlos llegar a los responsables políticos y a la opinión pública tienen en este momento un valor especial. Es fundamental generar y apoyar nuevas iniciativas como la liderada por la Sociedad Española de Pedagogía junto con otras ocho sociedades, para que la perspectiva de las Ciencias de la Educación esté presente en el debate sobre la evaluación de la producción científica y otros temas no menos importantes como las iniciativas legislativas en materia educativa o el nicho profesional que le corresponde a la Pedagogía, la Psicopedagogía o la Educación Social.

\section{Notas}

${ }^{1}$ Puede consultarse en la dirección http://www.sepedagogia.es/?p=94

${ }^{2}$ http://epuc.cchs.csic.es/SPI/

\section{Referencias bibliográficas}

Aliaga, Francisco M., y Correa, Ana D. (2011). Tendencias en la normalización de nombres de autores en publicaciones científicas. RELIEVE, 17 (1), 0. Recuperado de: http://www.uv.es/RELIEVE/v17n1/ RELIEVEv17nl_0.htm.

De Juanas Oliva, Á., y Beltrán Llera, J. A. (2014). Valoraciones de los estudiantes de ciencias de la educación sobre la calidad de la docencia universitaria. Educación XX1, 17 (1), 59-82. DOI: 10.5944/educxx1.17.1.10705.

Galán, A., (2013). Incertidumbres y desafíos de la universidad española. Escenarios posibles a corto y medio plazo. Avances en supervisión educativa, 19. Recuperado de: http://www.adide.org/revista/ images/stories/revista19/ase19_mono08.pdf.

Galán, A., y Serrano, C. (2006). Tendencias actuales en la evaluación externa del profesorado universitario: el caso de la ACAP. Miscelánea Comillas. Revista de Ciencias Humanas y Sociales, 64 (124), 127-171. Recuperado de: https://www.researchgate.net/profile/Arturo_Galan/publication/260892410_ Tendencias_actuales_en_la_evaluacin_externa_del_profesorado_universitario_el_caso_de_la_ ACAP/file/6a85e53314a64181dc.pdf?origin=publication_detail.

Galán, A., y Zych, I. (2011). Análisis de los criterios de la Comisión Nacional Evaluadora de la Actividad Investigadora (CNEAI) para la concesión de los tramos de investigación en Educación. Bordón. Revista de pedagogía, 63 (2), 117-139. Recuperado de: http://dialnet.unirioja.es/descarga/ articulo/3657124.pdf.

Real Decreto 1086/1989, de 28 de agosto de 1989, sobre retribuciones del profesorado universitario.

Tirado, Ramón, y Aguaded, J. Ignacio (2012). Influencia de las medidas institucionales y la competencia tecnológica sobre la docencia universitaria a través de plataformas digitales. RELIEVE, 18 (1), 4. Recuperado de: http://www.uv.es/RELIEVE/v18n1/RELIEVEv18n1_4.htm 